\title{
Self-confidence and knowledge of suicide assessment and prevention amongst first-line health professionals in Nelson Mandela Bay, South Africa
}

\begin{tabular}{|c|c|}
\hline \multicolumn{2}{|c|}{$\begin{array}{l}\text { Author: } \\
\text { Adeyinka A. Alabi', (D) }\end{array}$} \\
\hline \multicolumn{2}{|c|}{$\begin{array}{l}\text { Affiliations: } \\
{ }^{1} \text { Department of Family } \\
\text { Medicine and Rural Health, } \\
\text { Dora Nginza Regional } \\
\text { Hospital, Gqeberha, } \\
\text { South Africa }\end{array}$} \\
\hline \multicolumn{2}{|c|}{$\begin{array}{l}{ }^{2} \text { Department of Family } \\
\text { Medicine and Rural Health, } \\
\text { Faculty of Health Sciences, } \\
\text { Walter Sisulu University, } \\
\text { Mthatha, South Africa }\end{array}$} \\
\hline \multicolumn{2}{|c|}{$\begin{array}{l}\text { Corresponding author: } \\
\text { Adeyinka Alabi, } \\
\text { adeyinkaalabi@yahoo.com }\end{array}$} \\
\hline \multicolumn{2}{|c|}{$\begin{array}{l}\text { Dates: } \\
\text { Received: } 20 \text { July } 2021 \\
\text { Accepted: } 16 \text { Oct. } 2021 \\
\text { Published: } 10 \text { Jan. } 2022\end{array}$} \\
\hline \multicolumn{2}{|c|}{$\begin{array}{l}\text { How to cite this article: } \\
\text { Alabi AA. Self-confidence and } \\
\text { knowledge of suicide } \\
\text { assessment and prevention } \\
\text { amongst first-line health } \\
\text { professionals in Nelson } \\
\text { Mandela Bay, South Africa. } \\
\text { S Afr Fam Pract. 2022;64(1), } \\
\text { a5377. https://doi. } \\
\text { org/10.4102/safp.v64i1.5377 }\end{array}$} \\
\hline \multicolumn{2}{|c|}{$\begin{array}{l}\text { Copyright: } \\
\text { (C) 2022. The Authors. } \\
\text { Licensee: AOSIS. This work } \\
\text { is licensed under the } \\
\text { Creative Commons } \\
\text { Attribution License. }\end{array}$} \\
\hline \multicolumn{2}{|c|}{ Read online: } \\
\hline 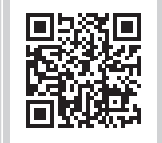 & $\begin{array}{l}\text { Scan this QR } \\
\text { code with your } \\
\text { smart phone or } \\
\text { mobile device } \\
\text { to read online. }\end{array}$ \\
\hline
\end{tabular}

Background: First-line health professionals are uniquely positioned to recognise suicidal behaviours in patients. However, the opportunities are often missed or poorly managed. Selfconfidence and knowledge of suicide prevention and assessment by health professionals can lead to prompt recognition and management of at-risk individuals. This study evaluates the first-line health professionals' self-confidence and knowledge of suicide assessment in Nelson Mandela Bay Municipality (NMBM), South Africa.

Methods: A cross-sectional study was conducted in six healthcare facilities across NMBM between January 2020 and March 2020. Five hundred first-line healthcare professionals were recruited to respond to a validated self-administered questionnaire to collect demographic characteristics, self-confidence levels and knowledge of suicide assessment and associated factors.

Results: A total of 344 first-line health professionals completed the questionnaire $(68.8 \%$ response rate); $40 \%$ of the respondents work in emergency units and $77.3 \%$ reported frequent encounters with patients who attempted suicide. Most participants had not received suicide assessment training during their undergraduate or postgraduate years $(59.6 \%$ and $81.1 \%$, respectively). They also lacked adequate knowledge and self-confidence in suicide assessment. Younger age, minimal work experience and attendance of two or more hours of suicide prevention training were associated with higher knowledge of suicide assessment.

Conclusion: Findings revealed gaps in self-confidence and knowledge of suicide management, attributed to lack of training in suicide management. Health authorities should prioritise upskilling of front-line workers in suicide prevention and assessment, specifically targeting older nurses in the region.

Keywords: suicide; suicide attempts; first-line health professionals; knowledge; competency.

\section{Introduction}

Worldwide, suicidal behaviour is a major public health concern, with an estimated 800000 people having died by suicide and many more attempting suicide every year. ${ }^{1}$ The low-income and moderate-income countries carried the brunt of the problem with over $75 \%$ of the suicide deaths. $^{2}$ Suicide is the end result of distressing complex interaction between biological, psychological and social crises, and is a preventable cause of deaths. ${ }^{3}$ Evidence-based effective preventative strategies include restriction of access to means of suicide, regular training of healthcare professionals in suicide prevention, increasing public awareness and optimal care of those with mental disorders. ${ }^{4,5}$

The World Health Organization (2012) identifies suicide as a preventable death if all the stakeholders play their role. ${ }^{6}$ In the majority of persons who died by suicide, there had been windows of opportunity open to first-line healthcare workers to interrupt the suicidal process but these were often missed or improperly managed. ${ }^{7}$ First-line healthcare professionals (nurses, general practitioners, family physicians, emergency department staff and clinical associates) are well placed to assist persons with occult suicidal behaviour through routine screening at the primary health centres. Many of the patients with ongoing suicidal behaviour present to first-line healthcare professionals with other complaints, without disclosing the suicidal intent. ${ }^{8,9,10}$ Firstline healthcare professionals need to possess a good clinical knowledge of suicide assessment to be able to identify patients with undisclosed ongoing suicidal behaviour, failure of which could result in missing patients planning imminent suicide. ${ }^{11,12}$ 
Furthermore, inadequate screening for depression and other mental illnesses by first-line healthcare professionals at the primary health care (PHC) level results in unrecognised and untreated mental illness. ${ }^{13,14,15}$ The volume of work, nonavailability of human and material resources and inadequate knowledge of healthcare professionals have been cited as contributory reasons for the poor detection and screening conducted by healthcare professionals at PHC facilities. ${ }^{16}$ Despite the devastating consequences of suicide on families, the health status and economy of a nation, there has been a paucity of published data on first-line healthcare professionals' knowledge and self-confidence in assessment of patients with suicidal behaviour in the Eastern Cape, South Africa. This study aimed to evaluate the first-line healthcare professionals' knowledge and self-confidence in conducting suicide assessments. The study objectives were to (1) evaluate first-line healthcare professional's knowledge of risk factors and warning signs of suicide (2) assess the selfconfidence of first-line healthcare professionals in assessment and management of patients with suicidal behaviour.

\section{Method \\ Study design and setting}

A multicentre cross-sectional study was conducted between 15 January 2020 and 15 March 2020 at health facilities in the Nelson Mandela Bay Municipality (NMBM) of South Africa. The municipality is situated in the western region of the Eastern Cape Province and consists of three urban cities; Gqeberha, Despatch and Uitenhage. The health structure in the municipality consists of three provincial hospitals, and 48 PHCs, out of which seven are community health centres (CHCs). Purposive sampling of six health facilities: two hospitals (Uitenhage provincial hospital and Dora Nginza regional hospital), two CHCs (Motherwell Health and Letitia Bam) and two PHCs (Rosedale and Mission vale) was conducted. The researcher's choice for the two provincial hospitals was because they offer primary and secondary level mental healthcare services. The CHCs and PHCs were selected based on the drainage areas of the two provincial hospitals. Dora Nginza hospital has 35-bed designated mental health unit and a 24-bed 72-hour mental health observation unit (72-hour unit). The designated unit has a full complement of psychiatrists, psychiatric registrars, clinical social workers, occupational therapists and clinical psychologists. The 72-hour unit is under the headship of family physician with medical officers, a psychologist and psychiatric nurses. The portal of entry for all mental healthcare users needing in-patient admission is casualty, where relevant medical workup is completed before onward transfer to the 72-hour unit. The mental healthcare services offered in the hospital include acute psychiatry, chronic inpatient care, outpatient clinics, liaison-consultation and rehabilitative services. Uitenhage provincial hospital has a 10-bed acute psychiatry ward and two of the feeder clinics were also selected as study sites. The four selected primary healthcare centres are being run by psychiatric nurses with a roving medical officer who visits each clinic once a week on a rotatory arrangement. Patients needing hospitalisation from the CHCs and PHCs are discussed and transferred to the provincial hospital of their drainage area.

\section{Sampling technique}

A targeted sample of 500 healthcare professionals was recruited from the six health facilities, from which 344 healthcare professionals completed the questionnaires (68.8\%). Participants were included in the study if they met the following criteria: 18 years and older, work in units with direct contact with patients who presented with suicidal behaviour and willing to participate in the study. Three trained research assistants distributed the questionnaire to be self-administered.

\section{Data collection and measures}

After obtaining informed consent, each participant completed a self-administered questionnaire. This questionnaire, which was previously validated in other studies, was used to collect data on demographics, knowledge and self-competence in suicide assessment. ${ }^{17,18}$ Participants were asked to rate their knowledge of suicide prevention on this seven-item questionnaire. Self-rating was carried out by ticking blocks on a Likert scale ranging from 1 (very low) to 5 (very high). Although all the items in the instrument were previously validated in other population, pilot study was conducted with the instruments amongst 10 first-line healthcare professionals in one of the study sites. Minor adjustments were made after reviewing the responses from the participants in the study. The results of the pilot study were excluded from the main study.

A more objective knowledge of suicide assessment was evaluated with eight-item agree or disagree questions, where the responses were scored as either correct or incorrect. The maximum and minimum obtainable scores of 0 and 8 , respectively, indicated that those with higher scores had greater knowledge.

The confidence of participants in assessment and management of patients with suicidal behaviour was assessed with threeitem questions rated on a 5 -point Likert scale ( 1 = strongly disagree, to $5=$ strongly agree). A minimum and maximum obtainable score of 1 and 15, respectively, indicated that those with higher score had greater confidence.

\section{Data analysis}

Participants' responses were coded and entered into Epi info version 3.5.3 software. Data analysis was performed using STATA software, version 15.0 (Stata Corporation, College Station, TX, United States [US]). Descriptive analyses (frequencies, percentage and standard deviations) were used to describe the demographic characteristics and to assess the level of knowledge and self-efficacy in suicide assessment. Chi-square test and bivariate analysis were used to assess associations between knowledge and independent variables. Variables that were significant at $p<0.05$ level were reported 
for factors associated with level of knowledge in suicide assessment and prevention.

\section{Results}

A total of 500 questionnaires were administered and 344 participants returned the questionnaires, thus, giving a response rate of $68.8 \%$. The participants comprised 216 nurses (62.8\%), 108 medical practitioners (31.4\%), 11 psychologists (3.2\%) and nine social workers $(2.6 \%)$. The majority of the participants were female $(n=246,71.5 \%)$ and 196 were 30 years and below (57.0\%). The majority of the participants reported not having received any training in suicide prevention during their undergraduate training $(n=205 ; 59.6 \%)$. Furthermore, most of the participants had not received any training on suicide prevention, postgraduation $(n=279 ; 81.1 \%)$. More than half $(n=189 ; 54.9 \%)$ of the participants reported having seen between 1 and 10 patients with suicidal behaviour in the previous month (Table 1).

\section{Knowledge of suicide assessment and prevention}

The result showed significant group differences in the mean total knowledge score with medical doctors having the highest score (mean 4.95) followed by social workers with an average score of 4.89 . Nurses had the lowest mean score of 3.77 (Table 2). Less than $40.0 \%$ of the participants rated themselves highly and very highly in the knowledge of suicide and prevention. About one-third (29.9\%) of the participants rated their general understanding about suicide prevention as 'high' or very 'high'. Only 32.6\% of the participants rated themselves as high or very high on how to ask someone if they have the feeling of committing suicide (Table 2).

However, just half of the sample performed well in the objective assessment of knowledge of suicide risk factors and warning signs. The first statement requiring either agreement or disagreement reads, 'People who talk about suicide do not kill themselves' to which $41 \%$ of the participants answered incorrectly. The correct response should have been to disagree. Statement two, requiring the same affirmation or rejection stated:

'[P]eople who make plans to commit suicide keep their thoughts to themselves to which $68 \%$ of the sample answered incorrectly. The correct answer should once again have been to disagree. The third statement reads, 'everyone who commits suicide is depressed'.

The correct response should have been to disagree. The fourth statement reads, 'Suicide tendencies are inherited, and suicide runs in families' and $39.8 \%$ of the participants answered incorrectly. The correct response should have been to disagree. The fifth statement, 'Removing the means of suicide would prevent many suicides' drew an incorrect answer from $48.5 \%$ of the participants. The correct response should have been to agree. The sixth statement, 'There are
TABLE 1: Background characteristics of healthcare workers included in the study.

\begin{tabular}{|c|c|c|}
\hline Variables & Frequency count & Percentage \\
\hline \multicolumn{3}{|l|}{ Age } \\
\hline 30 years or less & 165 & 48.0 \\
\hline $31-40$ years & 95 & 27.6 \\
\hline $41-50$ years & 52 & 15.1 \\
\hline $51-60$ years & 32 & 9.3 \\
\hline \multicolumn{3}{|l|}{ Gender } \\
\hline Male & 98 & 28.5 \\
\hline Female & 246 & 71.5 \\
\hline \multicolumn{3}{|l|}{ Home language } \\
\hline English & 65 & 18.9 \\
\hline Afrikaans & 63 & 18.3 \\
\hline Xhosa & 199 & 57.8 \\
\hline Others & 17 & 4.9 \\
\hline \multicolumn{3}{|l|}{ Profession } \\
\hline Medical doctor & 108 & 31.4 \\
\hline Nurse & 216 & 62.8 \\
\hline Psychologist & 11 & 3.2 \\
\hline Social worker & 9 & 2.6 \\
\hline \multicolumn{3}{|l|}{ Year of experience } \\
\hline $1-2$ years & 104 & 30.2 \\
\hline $3-5$ years & 76 & 22.1 \\
\hline $6-10$ years & 75 & 21.8 \\
\hline$>10$ years & 89 & 25.9 \\
\hline \multicolumn{3}{|l|}{ Workplace } \\
\hline Clinics & 105 & 30.5 \\
\hline Dora Nginza & 188 & 54.7 \\
\hline Uitenhage Hospital & 51 & 14.8 \\
\hline \multicolumn{3}{|c|}{ Unit of primary assignment } \\
\hline 72-h ward & 33 & 9.6 \\
\hline Psychiatry ward & 22 & 6.4 \\
\hline Casualty & 136 & 39.5 \\
\hline Medical ward & 71 & 20.6 \\
\hline Maternity & 61 & 17.7 \\
\hline Not stated & 21 & 6.1 \\
\hline \multicolumn{3}{|c|}{ Duration of undergraduate training in suicide assessment } \\
\hline None & 205 & 59.6 \\
\hline $0-1 \mathrm{~h}$ & 40 & 11.6 \\
\hline $2-3 \mathrm{~h}$ & 70 & 20.3 \\
\hline $4 \mathrm{~h}$ and more & 29 & 8.4 \\
\hline \multicolumn{3}{|c|}{ Duration of postgraduate training in suicide assessment } \\
\hline None & 279 & 81.1 \\
\hline $0-1 \mathrm{~h}$ & 27 & 7.8 \\
\hline $2-3 \mathrm{~h}$ & 20 & 5.8 \\
\hline $4 \mathrm{~h}$ and more & 18 & 5.2 \\
\hline \multicolumn{3}{|c|}{ Number of suicide patients seen in the past year } \\
\hline Zero & 78 & 22.7 \\
\hline $1-10$ & 149 & 43.3 \\
\hline $11-20$ & 39 & 11.3 \\
\hline $21-30$ & 41 & 11.9 \\
\hline 31 and more & 37 & 10.8 \\
\hline \multicolumn{3}{|c|}{ Number of SP seen last month } \\
\hline Zero & 142 & 41.3 \\
\hline $1-10$ & 189 & 54.9 \\
\hline 11 and more & 13 & 3.8 \\
\hline
\end{tabular}

$\mathrm{SP}$, suicidal behaviour patients.

one or two causes or motives that explain most suicides' evoked an incorrect answer from $41 \%$ of the participants. The correct response should have been to agree. The seventh statement read, 'There is no relationship between drugs/alcohol and suicide' and 33.4\% of the participants answered incorrectly. The correct response should have 
been to disagree. The eighth statement, 'Suicide is always the action of a patient suffering from a mental- or psychotic illness'. To this, $43 \%$ of the participants answered incorrectly. It would have been correct to have disagreed. The operative word in the statement was 'always' and this could not have been proven empirically.

\section{Association between baseline characteristics and knowledge of suicide prevention}

As shown in Table 2, participants aged 30 years or less, male gender, being medical doctors and having attended two or more hours of training whether in undergraduate or postgraduate were associated with high knowledge of suicide prevention and assessment.

\section{Self-confidence in suicide assessment}

Out of all the participants, 105 confirmed that they were hesitant to ask a patient if he or she is having suicidal tendency $(30.5 \%)$. About $40.0 \%$ of the participants reported being confident in their ability to successfully assess patients

TABLE 2: Association between background characteristics and knowledge of suicide.

\begin{tabular}{|c|c|c|c|c|}
\hline $\begin{array}{l}\text { Interdependent } \\
\text { variable }\end{array}$ & Frequency & $\begin{array}{c}\text { Average } \\
\text { Knowledge } \\
\text { scores (s.d.) }\end{array}$ & s.d. & $p$-value \\
\hline \multicolumn{5}{|l|}{ Age } \\
\hline 30 years or less & 165 & 4.35 & 1.38 & 0.053 \\
\hline $31-40$ years & 95 & 4.03 & 1.12 & \\
\hline $41-50$ years & 52 & 3.88 & 1.28 & \\
\hline $51-60$ years & 32 & 4.44 & 1.58 & \\
\hline \multicolumn{5}{|l|}{ Gender } \\
\hline Male & 98 & 4.43 & 1.31 & 0.044 \\
\hline Female & 246 & 4.11 & 1.32 & \\
\hline \multicolumn{5}{|l|}{ Qualifications } \\
\hline Medical doctor & 108 & 4.95 & 1.20 & $<0.001$ \\
\hline Nurse & 216 & 3.77 & 1.22 & \\
\hline \multicolumn{5}{|c|}{ Year of experience } \\
\hline $1-2$ years & 104 & 4.47 & 1.17 & 0.072 \\
\hline $3-5$ years & 76 & 4.14 & 1.37 & \\
\hline $6-10$ years & 75 & 3.97 & 1.35 & \\
\hline$>10$ years & 89 & 4.12 & 1.40 & \\
\hline \multicolumn{5}{|c|}{ Duration of undergraduate training in SP } \\
\hline None & 205 & 3.84 & 1.22 & $<0.001$ \\
\hline $0-1 \mathrm{~h}$ & 40 & 4.55 & 1.32 & \\
\hline $2-3 \mathrm{~h}$ & 70 & 4.89 & 1.15 & \\
\hline $4 \mathrm{~h}$ and more & 29 & 4.62 & 1.59 & \\
\hline \multicolumn{5}{|c|}{ Duration of postgraduate training in suicide assessment } \\
\hline None & 279 & 4.06 & 1.30 & 0.001 \\
\hline $0-1 \mathrm{~h}$ & 27 & 4.70 & 1.17 & \\
\hline $2-3 \mathrm{~h}$ & 20 & 5.0 & 1.34 & \\
\hline $4 \mathrm{~h}$ and more & 18 & - & 1.46 & \\
\hline
\end{tabular}

SP, suicidal behaviour patients; s.d., standard deviation. with suicidal behaviour and fewer participants (32.5\%) were confident in the management of patients with suicidal behaviour (32.5\%) (Table 3).

\section{Discussion}

Given the unique position of the front-line healthcare professionals in encountering individuals with suicidal behaviour at the healthcare facilities, missed opportunities to detect and manage people who may have suicidal ideations and plans may lead to catastrophic outcomes. This study seeks to assess the knowledge and self-confidence of first-line healthcare professionals in the assessment and management of suicide. This study shows that the majority of first-line healthcare professionals do not have sufficient knowledge of suicide assessment. The mean score in the objective assessment of knowledge was only half of the total obtainable score (4.59). Whilst medical doctors (4.95) and social workers attained just above half of the total obtainable score, nurses attained less than half of the total obtainable (3.77). In the self-rating of knowledge of suicide assessment and management, less than $30 \%$ of the participants rated themselves 'highly' or 'very highly'. Furthermore, more than half of the participants did not have confidence in assessing and managing patients with suicidal behaviour. These findings raise a great deal of concern, bearing in mind the cardinal role of first-line healthcare professionals in suicide prevention.

Our findings are in tandem with what was reported in a Kenyan study where nurses working in an emergency unit felt that they had inadequate knowledge and lacked confidence to assess patients with suicidal behaviour. ${ }^{19}$ Our findings are also consistent with a study conducted in the United States where more than $60 \%$ of the healthcare professionals felt incompetent and unskilled in suicide risk assessment. ${ }^{20}$ Medical practitioners and social workers had higher mean scores in the objective assessment of knowledge of suicide than nurses did. These findings are consistent with the result of Crawford et al., ${ }^{21}$ in London, where non-psychiatry doctors had greater knowledge of suicide prevention than non-psychiatry nurses. A plausible explanation for this could be lesser involvement of nurses in suicide assessment. Another likely cause of nurses having the least mean score could be the lower attendance of suicide prevention education amongst nurses than medical doctors. Therefore, to achieve a reduction in suicide rates, there is also a need to capacitate nurses in the area of suicide assessment and management.

In this study, the majority of the participants reported having had regular contact with patients with suicidal behaviour.

TABLE 3: Self-competency to treat suicidal behaviour patients.

\begin{tabular}{|c|c|c|c|c|c|c|c|c|c|c|}
\hline \multirow[t]{2}{*}{ Items } & \multicolumn{2}{|c|}{ Strongly disagree } & \multicolumn{2}{|c|}{ Disagree } & \multicolumn{2}{|c|}{ Undecided } & \multicolumn{2}{|c|}{ Agree } & \multicolumn{2}{|c|}{ Strongly agree } \\
\hline & $n$ & $\%$ & $n$ & $\%$ & $n$ & $\%$ & $n$ & $\%$ & $n$ & $\%$ \\
\hline I am confident in my ability to successfully assess suicidal patients & 47 & 13.7 & 72 & 20.9 & 86 & 25.0 & 111 & 32.3 & 28 & 8.1 \\
\hline I am confident in my ability to successfully treat suicidal patients & 51 & 14.8 & 99 & 28.8 & 82 & 23.8 & 95 & 27.6 & 17 & 4.9 \\
\hline I am hesitant to ask patients if he or she is having suicidal behaviour & 54 & 15.7 & 128 & 37.2 & 57 & 16.6 & 88 & 25.6 & 17 & 4.9 \\
\hline
\end{tabular}


However, only about $40 \%$ of the participants had received training in suicide assessment during undergraduate periods. This finding is consistent with Saini et al..$^{22}$ where only $33 \%$ of the primary healthcare professionals had received training in suicide assessment. The low level of knowledge of suicide assessment amongst participants in our study could be attributed to a lack of training in suicide assessment during and after their professional training. Further study will be needed to appraise the curriculum of nursing and medical schools to establish whether there is adequate coverage of suicide assessment and management.

The level of knowledge of suicide assessment was higher amongst those professionals who had two or more hours of training in suicide prevention in our study. This finding is consistent with previous studies which demonstrated an increase in healthcare professionals' knowledge of suicide assessment after attending suicide prevention training ${ }^{22,23,24}$

In this study, being a healthcare professional aged 30 years or less, with a shorter period of employment, yielded that this group had higher levels of knowledge of suicide assessment than older professionals did. Our result is consistent with that which has been reported in previous studies. ${ }^{25,26}$ The higher mean level of knowledge of suicide assessment amongst younger professionals could be attributed to increased public health concerns of suicide in recent times and possibly more time having been dedicated to suicide prevention during the younger professionals' training.

\section{Study limitations}

Many health professionals did not return the questionnaire and could not be followed up during the national lockdown because of COVID-19 pandemic. Self-reported knowledge and self-confidence may not necessarily represent a true reflection of the participants' practice and could be affected by social desirability bias. However, anonymous collection of data allowed the participants to provide their candid responses.

\section{Conclusion and recommendation}

The study shows a low level of self-confidence and knowledge of suicide assessment amongst healthcare professionals working in the health institutions in Nelson Mandela Municipality, Eastern Cape. The study further demonstrated a significant association between attendance of training in suicide prevention and knowledge of suicide assessment. It is, therefore, imperative to have a planned, scheduled inservice training for healthcare professionals in suicide assessment and management at their workstations. This would empower the professionals without disrupting their service delivery.

Improving the staff strength of mental health units of the provincial hospitals will also allow outreaching of clinicians to various PHCs to assist in capacity building of staff at the PHCs. Staff at various facilities should also be encouraged to attend some online educational continuing professional development (CPD) courses that focus on recognition and management of patients with suicidal behaviour. Provision of suicide educational posters, information booklets and standardised guidelines on suicide risks, step wise management, admission criteria and referral pathways should be made available at the workstations of all healthcare facilities in the municipality.

\section{Acknowledgements}

The author would like to thank all the health professionals who took part in the study.

\section{Competing interests}

The author declares that she has no financial or personal relationships that may have inappropriately influenced her in writing this article.

\section{Author's contributions}

A.A.A. conceptualised, designed and implemented the study protocol. A.A.A. guided data analysis and drafted the manuscript.

\section{Ethical consideration}

Ethical approval was obtained from Walter Sisulu University's Ethics Committee (reference: 038/2019) and permission was obtained from the Department of Health (reference: EC_201912005). In addition, permission was obtained from the management of the selected health facilities prior to the implementation of the study protocol. All the participants gave written informed consent demonstrating their willingness to voluntarily participate in the study. There was no financial inducement for participation. More so, each participant received an information leaflet detailing the purpose and process of the study. The right to privacy and confidentiality of medical information was respected during and after the study. All research processes followed the Helsinki Declaration and also laid out ethical procedures accordingly.

\section{Funding information}

A.A.A. received financial support from the Discovery Health Foundation, South Africa, towards the implementation of this study.

\section{Data availability}

I wish to confirm that the data supporting the findings of this study are available within the article.

\section{Disclaimer}

The discussion and conclusion in this article are those of the author and does not necessarily reflect official position of Walter Sisulu University. 


\section{References}

1. World Health Organization (WHO). Suicide data [homepage on the Internet] [cited $2020 \mathrm{Feb}$ 08]. Available from: http://www.who.int/mental_health/ prevention/suicide/suicideprevent/en

2. lemmi V, Bantjes J, Coast E, et al. Suicide and poverty in low-income and middleincome countries: A systematic review. Lancet Psychiatry. 2016;3(8):774-783. https://doi.org/10.1016/S2215-0366(16)30066-9

3. WHO. Preventing suicide: A global imperative [homepage on the Internet] Luxembourg: World Health Organization; 2014 [cited 2020 Feb 09]. Available from: https://apps.who.int/iris/bitstream/handle/10665/131056/9789241564779-ger. pdf

4. Lygnugaryte-Griksiene A, Leskauskas D, Jasinskas N, Masiukiene A. Factors influencing the suicide intervention skills of emergency medical services providers. Med Educ Online. 2017;22(1):1291869. https://doi.org/10.1080/1087 providers. Med Educ

5. Zalsman $G$, Hawton $K$, Wasserman $D$, et al. Suicide prevention strategies revisited: 10-year systematic review. Lancet Psychiatry. 2016;3(7):646-659. https://doi. org/10.1016/S2215-0366(16)30030-X

6. World Health Organization. Public health action for the prevention of suicide: A framework [homepage on the Internet]. 2012 [cited 2021 Feb]. Available from: http://apps.who.int/iris/bitstream/10665/75166/1/9789241503570_eng.pdf

7. Pearson A, Saini $P, D a$ Cruz D, et al. Primary care contact prior to suicide in individuals with mental illness. Br J Gen Pract. 2009;59(568):825-832. https://doi. org/10.3399/bjgp09X472881

8. Allen $\mathrm{MH}, \mathrm{Abar} \mathrm{BW}, \mathrm{McC}$ rmick $\mathrm{M}$, et al. Screening for suicidal ideation and attempts among emergency department medical patients: Instrument and results from the psychiatric emergency research collaboration. Suicide Life Threat Behav. 2013;43(3):313-323. https://doi.org/10.1111/sltb.12018

9. Claassen CA, Larkin GL. Occult suicidality in an emergency department population. Br J Psychiatry. 2005;186(4):352-353. https://doi.org/10.1192/bjp.186.4.352

10. Shaw EK, Howard J, Clark EC, Etz RS, Arya R, Tallia AF. Decision-making processes of patients who use the emergency department for primary care needs. J Health Care Poor Underserv. 2013;24(3):1288-1305. https://doi.org/10.1353/ hpu.2013.0140

11. McCarthy JF, Bossarte RM, Katz IR, et al. Predictive modeling and concentration of the risk of suicide: Implications for preventive interventions in the US Department of Veterans Affairs. Am J Public Health. 2015;105(9):1935-1942. https://doi. of Veterans Affairs. Am J Public
org/10.2105/AJPH.2015.302737

12. Stuber J, Quinnett P. Making the case for primary care and mandated suicide prevention education. Suicide Life Threat Behav. 2013;43(2):117-124. https://doi. org/10.1111/sltb.12010

13. Lancet Global Mental Health Group, Chisholm D, Flisher AJ, et al. Scale up services for mental disorders: A call for action Lancet. 2007;370(9594):1241-1252. https://doi.org/10.1016/S0140-6736(07)61242-2
14. Gureje O, Abdulmalik J, Kola L, Musa E, Yasamy MT, Adebayo K. Integrating mental health into primary care in Nigeria: Report of a demonstration project using the mental health gap action programme intervention guide. BMC Health Serv Res. mental health gap action programme intervention guide. BMC

15. Lotfi L, Flyckt L, Krakau I, Mårtensson B, Nilsson GH. Undetected depression in primary healthcare: Occurrence, severity and co-morbidity in a two-stage procedure of opportunistic screening. Nord J Psychiatry. 2010;64(6):421-427. procedure of opportunistic screening. Nord
https://doi.org/10.3109/08039481003786378

16. Udedi M. The prevalence of depression among patients and its detection by primary health care workers at Matawale Health Centre (Zomba). Malawi Med J. 2014 [cited 2021 Nov 21];26(2):34-37. Available form: http://www.ncbi.nlm.nih. gov/pubmed/25157314

17. Quinnett P. QPR gatekeeper training for suicide prevention: The model, rationale, and theory. 2007 [cited $2008 \mathrm{Jul}$ 28]. Available from: https://www.researchgate. net/publication/254002929_QPR_Gatekeeper_Training_for_Suicide_ Prevention_The Model Rationale_and-Theory

18. Van Landschoot R, Portzky G, Van Heeringen K. Knowledge, self-confidence and attitudes towards suicidal patients at emergency and psychiatric departments: A randomised controlled trial of the effects of an educational poster campaign. Int J Environ Res Public Health. 2017;14(3):304. https://doi.org/10.3390/ijerph14030304

19. Maina R, Bukusi D, Njuguna SK, Kumar M. Gaps in suicide assessment and management among accident and emergency nurses in Kenyatta National Hospital: A qualitative study. Glob Soc Welf. 2019;6(2):87-96. https://doi.org/ 10.1007/s40609-018-0127-7

20. Betz ME, Sullivan AF, Manton AP, et al. Knowledge, attitudes, and practices of emergency department providers in the care of suicidal patients. Depress Anxiety. 2013;30(10):1005-1012. https://doi.org/10.1002/da.22071

21. Crawford T, Geraghty W, Street K, Simonoff E. Staff knowledge and attitudes towards deliberate self-harm in adolescents. J Adolesc. 2003;26(5):619-629. https://doi.org/10.1016/S0140-1971(03)00060-5

22. Saini VK, Gehlawat P, Gupta T. Evaluation of knowledge and competency among nurses after a brief suicide prevention educational program: A pilot study. J Fam Med Prim Care. 2020;9(12):6018. https://doi.org/10.4103/jfmpc.jfmpc_984_20

23. Chan SW, Chien WT, Tso S. Evaluating nurses' knowledge, attitude and competency after an education programme on suicide prevention. Nurse Educ Today. 2009;29(7):763-769. https://doi.org/10.1016/j.nedt.2009.03.013

24. Santos JC, Simões RMP, Erse MPQdA, Façanha JDN, Marques LAFA. Impact of '+ Contigo' training on the knowledge and attitudes of health care professionals about suicide. Rev Latin Am Enfermag. 2014;22(4):679-684. https://doi.org/ about suicide. Rev Latin Am Enf
10.1590/0104-1169.3503.2467

25. Kawanishi C, Sato R, Yamada T, Ikeda H, Suda A, Hirayasu Y. Knowledge and attitudes of nurses, nursing students and psychiatric social workers concerning current suicide-related issues in Japan. Prim Care Ment Health. 2006;4(4):285.

26. Fekadu $A$, Demissie $M$, Birhane $R$, et al. Under detection of depression in primary care settings in low and middle-income countries: $A$ s meta-analysis. MedRxiv. 2020. https://doi.org/10.1101/2020.03.20.20039628 